\title{
A globalização periférica e a ressignificação dos lugares
}

Recebido: 30.07.20 Aprovado: 01.09.20
Jacob Carlos Lima*

Resumo: Neste artigo, buscamos analisar as novas configurações do trabalho decorrentes dos processos de reestruturação industrial e da inserção de novos territórios à lógica da produção capitalista global. Discutimos processos de reespacialização de setores industriais favorecidos pela guerra fiscal entre governos estaduais e municipais e sua ressignificação em locais sem tradição industrial ou de trabalho organizado. As redes de terceirização incorporam territórios antes vinculados a atividades agrícolas tradicionais, ou estagnadas economicamente, que fornecem mão de obra barata e escolarizada. Nosso argumento é o de que essas situações permitem entender a incorporação econômica de regiões periféricas dentro do país num quadro de expansão de mercados globais, impactando nas relações sociais vigentes. O local se integra ao global de formas distintas, mas complementares e heterogêneas, hibridizando formas de trabalho e ocupação dentro da lógica da acumulação. Temos como recorte empírico três setores produtivos distribuídos em sub-regiões do Nordeste, que são representativos das distintas formas de trabalho utilizado e o lugar se constitui numa variável relevante: o setor de confecções, o da produção de software e o da indústria automotiva, todos profundamente integrados em cadeias globais de valor. Esses setores caracterizam a integração da região aos fluxos globais, nos quais múltiplas globalizações se interlaçam.

Palavras-chave: Globalização periférica. Reespacialização. Global-local. Ressignificação de territórios. Trabalho.

\section{Peripheral globalization and the resignification of places}

Abstract: This article analyzes the new configurations of labor resulting from processes of industrial restructuring and the insertion of new territories into the logic of the global capitalist production. It discusses the re-spatialization processes of industrial sectors favored by the fiscal war between states and municipal governments, and their re-signification in places without an industrial tradition or organized labor. Outsourcing networks incorporate territories previously linked to traditional agricultural activities, or economically stagnant, which provide cheap and educated labor. Our argument is that these situations make it possible to understand the economic incorporation of peripheral regions in global markets, and the impact on current social relations. The place is integrated with the global in distinct, but complementary and heterogeneous ways, hybridizing forms of labor and occupation within the logic of accumulation. We selected three productive sectors in sub-regions of the Northeast, which are representative of the different forms of labor relations where the place is a relevant variable: the clothing sector, software production, and the automotive industry, all deeply integrated into global value chains. These sectors characterize the region's integration into global flows, in which intertwine multiple globalizations.

Keywords: Peripheral globalization. Re-spatialization. Global-local. Re-signification of territories. Labor.

\author{
*Professor titular \\ no Departamento \\ de Sociologia da \\ Universidade Federal \\ de São Carlos \\ (UFSCar), São Carlos, \\ SP, Brasil. \\ Orcid: 0000-0001- \\ 6475-9575. \\ <calimajb@gmail. \\ com>.
}




\section{Introdução}

N

este artigo buscamos analisar as novas configurações do trabalho decorrentes dos processos de reestruturação industrial e da inserção de novos territórios à lógica da produção capitalista global. Discutimos os processos de reespacialização de setores industriais favorecidos pela guerra fiscal entre governos estaduais e municipais e sua ressignificação em locais sem tradição industrial ou de trabalho organizado. As redes de terceirização incorporam territórios antes vinculados a atividades agrícolas tradicionais, ou estagnadas economicamente, que fornecem mão de obra barata e escolarizada.

Nosso argumento é o de que essas situações permitem entender a incorporação econômica de regiões periféricas dentro do país, num quadro de expansão de mercados globais impactando nas relações sociais vigentes. O local se integra ao global de formas distintas, mas complementares e heterogêneas, hibridizando formas de trabalho e ocupação, mobilizando diversos atores sociais. O Estado é agente fundamental nesse processo, seja na implementação de políticas em conjunto com empresas privadas - no sentido de alavancar processos de terceirização através de incentivos fiscais, empréstimos a juros baixos e oferecimento de infraestrutura para atrair investimentos nas regiões -, seja para favorecer o desenvolvimento de núcleos produtivos já existentes, através também de incentivos fiscais, bem como da propagação de formação especializada através de cursos regulares, ou de cursos de formação específicos de gestão e empreendedorismo, mobilizando o "capital" espacial do local.

Quando falamos em globalização, tendemos a privilegiar a questão da mobilidade do capital e do trabalho, mesmo tendo em conta que essas mobilidades têm velocidades e entraves diferenciados. Por outro lado, as categorias de lugar e processos de trabalho (Sassen: 2007) permitem recuperar a imersão local desses processos de globalização, e aqui expandimos as considerações de Saskia Sassen não apenas para as grandes cidades e/ou zonas francas de exportação, mas para territórios historicamente fora desses processos, nos quais as tecnologias informacionais e de transporte atenuam distâncias, havendo ainda a incorporação das culturas do trabalho preexistentes, as quais são adequadas às necessidades do capital inseridas de forma direta ou indireta através de redes de terceirização.

Os conceitos de espaço, território e lugar têm sido fartamente discutidos, sendo que poderíamos destacar o espaço como construção social através de sentidos atribuídos à sua materialidade física e geográfica. Nem sempre fica clara a distinção entre espaço e território, aceitando-se no geral o caráter político presente no ter- 
ritório, onde o espaço social representa relações sociais de poder e dominação. $\mathrm{Na}$ globalização, o território assume uma característica reticular e de ressignificação constante em função da mobilidade do capital e do trabalho, no qual os lugares, aqui complementando o significado dos territórios, incorporam as práticas sociais e os sentidos atribuídos no dia a dia ${ }^{1}$.

Temos como recorte empírico três setores produtivos distintos entre si, mas que são representativos das formas de trabalho para as quais o lugar é uma variável relevante: o setor de confecções, o da produção de software e o da indústria automotiva, todos profundamente integrados em cadeias globais de valor. Apresentamos três situações em sub-regiões do Nordeste que caracterizam a integração da região aos fluxos globais, nos quais múltiplas globalizações se interlaçam num contexto periférico ao capitalismo no Brasil.

i. Na primeira situação, recuperamos a produção têxtil e de confecções em municípios do Seridó norte-riograndense. Um projeto governamental de terceirização para o setor de confecções no interior do estado, o Pró-Sertão, foi pensado para atender um grupo local que atua nacionalmente através de uma cadeia de lojas, assim como outros grupos que passaram a utilizar o projeto. Esse projeto constou da abertura de facções em pequenas cidades próximas a Caicó, cidade conhecida por sua "vocação têxtil" decorrente da produção de algodão, que durou até a praga do bicudo nos anos 1970, e da existência de uma pequena produção, a maioria informal, de redes, tapetes e panos de prato e bonelaria. A terceirização representada pelas facções tornou-se a principal atividade local, com a finalização de peças de confecções que são consumidas nacionalmente. Na produção têxtil de produtos consumidos regionalmente, assiste-se a uma entrada de tecidos chineses mais baratos e a uma distribuição nacional de artigos de baixo custo como panos de prato, panos de chão, entre outros.

ii. A segunda situação traz a análise do setor de produção de software, atividade em crescimento no país dada a informatização crescente das atividades econômicas. Ora entendida como indústria, ora como serviços, tornou-se fundamental em todos os processos produtivos. Como setor econômico, no Brasil, surge na década de 1990 com a expansão dos computadores pessoais e da internet. Uma de suas características estaria no caráter desterritorializado e virtual da produção, seu controle sendo feito por grandes empresas, e sendo formada por pequenas e médias empresas que atendem clientes customizando
1. Para uma recuperação histórica do conceito de território utilizado na geografia e na sociologia, veja-se Marcos Aurélio Saquet (2010). 
2. A pesquisa foi realizada entre 2017 e 2020, dentro do Projeto Universal CNPq (402354/20168) "Trabalho e globalização periférica: estudo de três setores produtivos". softwares que são distribuídos por todo o país. Apresentamos esse setor na cidade de João Pessoa, em empresas organizadas em grande medida a partir de alunos e professores das universidades federais do estado que trabalham terceirizadas, ou prestam serviços para empresas nacionais e internacionais.

iii. A terceira situação estuda a instalação de uma fábrica de automóveis na região conhecida como "Mata Norte", na cidade de Goiana, no estado de Pernambuco. Resulta do processo de deslocamento da indústria automobilística, que, a partir dos anos 1990, teve uma grande expansão no país, resultante de generosos incentivos fiscais, de um mercado interno potencialmente atraente, decorrente de políticas de estabilização cambial e que, nos governos da década seguinte, se beneficiou da valorização do salário-mínimo e da expansão do crédito e do consumo dos setores populares $O$ deslocamento significou uma desconcentração dessa indústria da região do $A B C$ paulista - cenário de grandes mobilizações sindicais nas décadas de 1970 e 1980 - e uma queda salarial significativa dos trabalhadores antes considerados a elite operária "fordista" do país. Trata-se de uma fábrica da Fiat-Chrysler assim como de 16 fornecedores de autopeças e implementos dentro do Programa de Aceleração do Crescimento (PAC). A implantação do parque fabril criou mais de 9.000 empregos diretos e indiretos para uma população ocupada anteriormente em atividades agrícolas e de coleta (marisqueiras), assim como mobilizou trabalhadores qualificados de outras regiões do país e mesmo do exterior.

A pesquisa constou de visitas exploratórias nos polos produtivos, em oficinas de produção, mercados e feiras de exposição de produtos e empresas, além de entrevistas com pequenos produtores, "empreendedores", vendedores ambulantes, gestores e trabalhadores².

\section{As múltiplas globalizações}

O conceito de globalização tem destacado o caráter de expansão global do capital em busca de menores custos de produção e novos mercados consumidores, incorporando novos territórios e novas populações aos fluxos da economia mercantil. Nesse processo, é estabelecida uma relação dialética entre o global e o local pelas transformações heterogêneas provocadas nos novos territórios que interagem com a economia mais ampla, reconfigurando o local social e culturalmente. Podemos nos referir aos processos de externalização industrial em países da periferia do 
capitalismo, na qual as fábricas instaladas provocam a proletarização de populações antes vinculadas a uma economia de subsistência e que se tornam, grosso modo, parte de um proletariado global. Essa interação é conhecida como glocalismo, quando as práticas sociais transformam e são transformadas por processos sociais mais amplos, mantendo, contudo, especificidades locais (Robertson, 2000; Roudmetof, 2019).

Numa outra acepção, temos a discussão de uma globalização popular ou de uma globalização por baixo, na qual a imigração para os países centrais reconfigura relações sociais e de trabalho existentes num quadro de reestruturação econômica no contexto de transformações conhecidas como neoliberais. A imigração impacta não apenas os países de acolhida, mas também os de origem, dinamizando economias locais que passam a contar com a ajuda de seus nacionais que trabalham no exterior. Vários estudos apontam nessa direção. Entre eles destacamos Alejandro Portes (1997), ao se referir aos imigrantes latino-americanos nos Estados Unidos; Alain Tarrius (2002), que trata dos imigrantes do Magreb na França; e Gustavo Lins Ribeiro (2010), ao se referir a uma globalização não hegemônica representada por mercados populares de mercadorias legais, ilegais e ilícitas que passam a compor cenários transnacionais, fronteiriços ou não, no qual circulam pessoas e mercadorias. Esses três autores apontam para a relativização do caráter legal dessa circulação e o difícil controle do contrabando em portos, aeroportos e fronteiras, dada a sua porosidade e as dificuldades de fiscalização. Assim, uma mercadoria produzida e comercializada legalmente num país pode entrar ilegalmente em outros. Nesse mercado inclui-se também a produção e a comercialização de drogas ilícitas cujo controle e repressão está longe de inibir o seu avanço.

Numa perspectiva que destaca as mobilidades presentes com as novas tecnologias de transportes e comunicações, Caroline Knowles (2014) apresenta o conceito de vias secundárias da globalização, demonstrando, a partir da trajetória de um chinelo, como a globalização se apresenta em vias principais e secundárias, formais e informais, legais e ilegais; analisa desde a extração de petróleo no Kuwait (com trabalhadores imigrantes do sul da Ásia) e o refino do petróleo na Coreia do Sul, até a produção do chinelo em unidades familiares na China, sua importação por sacoleiros etíopes que entram pelo Chifre da África, o descarte nos lixões de Adis Abeba e sua retomada a partir da coleta por catadores de recicláveis, com o reinício do ciclo produtivo. Produção, distribuição e consumo se integram em processos globais, nos quais mercadorias e trabalhadores se inserem com os vínculos mais variados.

Essas mobilidades pressupõem a compressão tempo-espaço destacada por autores como Roland Robertson (1999), David Harvey (1993), Anthony Giddens (1991), 
John Urry (2000), Manuel Castells (2003), que destacam a importância da revolução tecnológica informacional, na qual os transportes adquirem um papel central, e que se convencionou chamar de capitalismo desorganizado, ou capitalismo flexível.

As novas tecnologias informacionais têm um peso crescente nessas reterritorializações e reconfigurações do trabalho. A virtualidade dessas tecnologias possibilita o controle da produção em qualquer parte do mundo, assim como a contratação de trabalhadores dos mais diversos tipos de qualificação. Ao manter a concentração dos investimentos nas chamadas cidades globais, nos centros de inovação e controle, reproduz hierarquizações centro-periferia em diversas dimensões. Isso é comum em setores de trabalho intensivo, como a produção de vestuário, mas se mantém também nos setores de conhecimento intensivo, como a produção e desenvolvimento de software. Empresas norte-americanas e europeias mantêm seus polos de inovação no Vale do Silício, em Londres, Berlim, Amsterdam e Estocolmo, bem como em cidades asiáticas como Tel Aviv, Pequim, Singapura, entre outras, e subcontratam engenheiros e outros profissionais em todo o mundo através do chamado trabalho remoto. Os desenvolvedores de software na Índia chegam a ganhar dez vezes menos que o trabalhador norte-americano; e, no Brasil, um desenvolvedor de software no Nordeste chega a ganhar um terço do que recebe o trabalhador de São Paulo. Além disso, empresas localizadas nas periferias também sofrem discriminações acerca de sua capacidade, bem como da qualidade de seus produtos, conforme sua localização territorial.

Vale destacar ainda que não estamos nos referindo a um capital transnacional, no sentido da perda do significado das fronteiras políticas e do controle do Estado nacional. Ao contrário, assiste-se o domínio de empresas norte-americanas, europeias e asiáticas, firmemente estabelecidas nacionalmente, o que se evidencia no conflito comercial entres os Estados Unidos e a China no controle da Internet $5 \mathrm{G}$, a quinta geração de conectividade móvel com maiores velocidades no acesso a dados, maior cobertura e maior estabilidade, prometendo com isso uma revolução nas formas de produção. Também podemos nos referir que num mesmo território nacional convivem distintas periferias que refletem a centralização dos espaços e sua vinculação internacional - como as grandes cidades referidas por Sassen - e sua hierarquização, que atende às formas como o capital se organiza nesse território.

A divisão internacional do trabalho se reproduz concentrando conhecimento nos países centrais e sua execução na periferia. A reespacialização da produção relocaliza apenas a execução, a montagem dos produtos. O setor de software é um 
exemplo disso, uma mão de obra qualificada, majoritariamente com ensino superior, mas sem o controle das tecnologias, utilizando linguagens monopolizadas por grandes empresas estrangeiras. O setor já nasce dentro de redes globais, embora o local o reconfigure. No caso da indústria automotiva, esta desloca a montagem a montagem de produtos para os países periféricos e raramente desenvolve produtos nesses países.. Sua relocalização nos remete às vias principais do grande capital financeiro e industrial e suas estratégias de venda e redução de custos. A produção de confecções se caracteriza por grande fragmentação em unidades produtivas, mas que se insere, tais como as demais, em cadeias de terceirização nacionais e internacionais, assim como a pesquisa tecnológica de materiais e equipamentos. Difere das demais pelos vínculos de trabalho diferenciados, pela sazonalidade da produção e as variações da moda, além do baixo custo da força de trabalho utilizada.

Nas periferias, temos a convivência desigual e combinada, num mesmo território, de diversos atores sociais, regimes de acumulação, graus tecnológicos que refletem a forma como o local se insere na dinâmica capitalista global. Num país de dimensão continental como o Brasil, convivem diferentes territórios com maior ou menor especialização, o que permite a compartimentalização e hierarquização de periferias pela oferta de força de trabalho local abundante e barata e os incentivos fiscais oferecidos por estados e municípios.

\section{Os territórios da precariedade: o setor de confecções}

Embora concentrado em São Paulo, o setor de confecções se expandiu por todo o país a partir dos anos 1990, com a reestruturação econômica que atingiu a indústria têxtil e de confecções. Essa reestruturação implicou no fechamento e na redução do número de grandes empresas, bem como com a entrada de produtos importados que obrigou o setor a se reorganizar, passando a trabalhar de forma terceirizada e a se inserir nas cadeias globais de produção (Kontic, 2007). Essa terceirização, seguida também pela quarteirização, encontrou no país uma força de trabalho abundante e barata, um mercado de consumo bastante dinâmico favorecendo a criação e expansão de polos produtivos e de comercialização espaIhados pelo país. De forma geral, a formalização das relações de trabalho convive com ampla informalização das atividades, seja numa metrópole como São Paulo, onde oficinas informais utilizam trabalhadores latino-americanos em situação ilegal, seja em pequenas cidades do interior do país, que se especializaram nesse tipo de produção e atuam majoritariamente na informalidade (Lima, 2015; Véras de Oliveira, 2013; Freire, 2009). 


\section{O Nordeste}

\section{e a terceirização industrial do setor}

A guerra fiscal que marcou os anos 1990 foi caracterizada por significativo deslocamento da produção do vestuário para o nordeste do país, com destaque para a indústria calçadista e as tentativas de implantação de processos de terceirização de confecções por fábricas do Sudeste e Sul que mantinham unidades na região. Entre essas tentativas, destacam-se a implementação de políticas de empresas, estado e prefeituras de abrir no interior dos estados pequenas unidades de produção que funcionavam no acabamento de produtos com salários bem abaixo daquele pago nas unidades das capitais regionais. Ou ainda na tentativa de organizar cooperativas de produção sobre o controle das empresas (Lima, 1999; 2002).

Essas tentativas, abortadas ora pela fiscalização do Ministério Público do Trabalho, ora pela crise das grandes empresas do setor, tiveram continuidade nas décadas seguintes com maior ou menor sucesso. Grupos empresariais buscaram reproduzir pequenas unidades produtivas no interior da Região Nordeste, evitando as capitais, em geral, com maior atuação sindical. No Rio Grande do Norte, elas foram implantadas na região do Seridó, conhecida anteriormente pela produção de algodão e existência de uma pequena produção têxtil majoritariamente voltada a produtos têxteis para uso doméstico. Nos inícios dos anos 2000, uma empresa de confecções local passou a terceirizar roupas para cadeias de lojas, constituindo o núcleo de um conjunto de facções que se expandiram a partir do apoio estatal.

Em 2013, o governo do estado, juntamente com um grupo empresarial, criou o Pró-Sertão, programa de incentivo ao empreendedorismo no setor, com apoio da Federação das Indústrias do estado, do Serviço Brasileiro de Apoio às Micro e Pequenas Empresas (Sebrae), do Serviço Nacional de Aprendizagem Industrial do Rio Grande do Norte (Senai-RN) - para a qualificação de mão de obra - e do Banco do Nordeste - como agente financiador para organizar facções para atuarem terceirizadas para empresas. Aos incentivos e financiamentos diretos, soma-se a expansão

3. Outros municípios com facções: CerroCorá, Acari, Parelhas, Equador, Cruzeta e Santana do Seridó, Assu e Messias Targino. Estimativas Instituto Brasileiro de Geografia e Estatística (IBGE, 2019). da estrutura educacional da região com a abertura, na cidade de Caicó, de um campus do Instituto Federal do Rio Grande do Norte, aberto em 2009, com três cursos técnicos na área: técnico têxtil, técnico do vestuário e um curso superior em tecnologia em design de moda, criado em 2013.

Foram organizadas aproximadamente 70 facções espalhadas por municípios da região, sendo que a maioria se encontra em São José do Seridó (4.634 habitantes) e Jardim do Seridó (12.396 habitantes)³, tanto em áreas urbanas como rurais. 
O principal grupo local mantinha sete das 18 facções existentes no município, com uma estrutura completa de uma fábrica de confecção que estava desenvolvendo uma marca própria para seus produtos, por ora distribuídos no Rio Grande do Norte. Cada unidade de facção empregava em torno de 35 trabalhadores(as). No município de São José, empregava em torno de 600 trabalhadores (Lima, Corteletti \& Araújo, 2020). O grupo atuava como terceirizada para redes de varejo, principalmente de uma empresa com sede no estado, trabalhando secundariamente para outras marcas nacionais e mesmo internacionais, mas sem a mesma regularidade da primeira. Utilizava maquinaria moderna até por exigência das contratantes, sendo que o grupo investia, como já foi dito, numa maior autonomia com relação às empresas primeiras. A força de trabalho era majoritariamente jovem e com ensino médio.

As relações de trabalho eram formalizadas, com ganhos de um salário-mínimo pelos trabalhadores, mas não existem contratos entre as facções e as empresas primeiras, o que torna a relação instável e constituiu-se em objeto de investigação do Ministério Público do Rio Grande do Norte, que considerou as facções como inseridas numa relação de subordinação funcionando como departamentos das empresas contratadas. Essa situação tem provocado igualmente instabilidade entre as facções, em razão da dependência de poucas empresas para sua manutenção e funcionamento.

A presença das facções nos municípios sem nenhuma outra atividade econômica significativa torna o emprego nas facções algo desejável e garante em alguns deles uma situação de quase pleno emprego. Numa unidade rural de São José do Seridó, no assentamento rural de Caatinga Grande, com 300 habitantes aproximadamente, 35 postos de trabalho mantinham parte da juventude local ocupada.

Essa situação explica a realização, no ano de 2017, da mobilização desses trabalhadores contra o Ministério Público do estado, que denunciou a principal empresa contratante e esta ameaçou parar de enviar encomendas às facções, inviabilizando-as ${ }^{4}$.

A aproximadamente 30 quilômetros de São José do Seridó, encontra-se o município de Jardim de Piranhas, com população estimada, segundo o IBGE, em 14.837 habitantes (em 2019), marcada por mais de 70 pequenas unidades produtivas, a maioria informal, com produção distribuída por sacoleiros e pequenos comerciantes para todo o país, e que funcionam desde os anos 1990.

A produção de Jardim de Piranhas decorre da produção de redes em municípios próximos, do lado paraibano da fronteira, e foi se especializando na produção de artefa-
4. Agora RN:

"Centenas de apoiadores do PróSertão protestam em São José do Seridó.

A manifestação acontece na mesma semana da realização da primeira audiência da Ação Civil Pública que o MPT está movendo contra a Guararapes". Publicado em 16 Set. 2017 às 13:22.

Disponível em: <https://agorarn. com.br/regionais/ centenas-deapoiadores-do-prosertao-protestamem-sao-jose-doserido/>. 
5. Um caso típico ideal da organização voluntária de produtores, com o crescimento e a consolidação de um polo de confecções $70 \%$ na informalidade, sendo considerado modelo de empreendedorismo, é o de Santa Cruz do Capibaribe, em Pernambuco, a 297 quilômetros de Caicó (Véras de Oliveira, 2013). tos para uso doméstico de baixo custo, como panos de prato, toalhas e tapetes, com destaque para os primeiros. A produção se estende por toda a cidade. É comum, na maioria dos quintais, os panos estarem secando em varais e em outras molduras, geralmente com o emprego de mão de obra familiar. Algumas unidades maiores, embora formalizadas, utilizam predominantemente o trabalho informal, através de formas distintas de terceirização e quarteirização. O maquinário é antigo e a modernidade da produção, se é que é possível se referir assim, encontra-se na entrada de tecidos chineses, considerados mais baratos, com o abandono da tecelagem e a concentração no corte, modelagem e estamparia. A comercialização mantém-se a partir de relações de confiança, sendo o WhatsApp a forma tecnológica mais usada. Mesmo assim, a produção, principalmente de panos de prato, abastece todo o mercado nacional. Neste caso, o Estado ainda está pouco presente, situação que tende a mudar, caso haja um aumento da produção, mas ainda incerta frente à crise econômica que tem afetado essa produção informal (Araújo \& Oliveira, 2020).

Temos duas experiências de produção nesse território: uma vinculada a redes de terceirização, a partir de experiências de interiorização industrial com atuação do Estado e de empresas privadas; e outra, em Jardim de Piranhas, com a constituição de um núcleo produtivo informal, voluntário, da produção de unidades familiares, aproveitando-se da proximidade com outros municípios produtores (no caso, redes e tapetes $)^{5}$. O local, nessas duas situações, vai se modificando, seja pela entrada do trabalho formal, terceirizado para grandes empresas, seja pela inserção, a conta gotas, da produção globalizada (produtos chineses) e a comercialização através de meios eletrônicos, ainda em pequena escala. Os pequenos municípios sertanejos permanecem em suas configurações tradicionais, mas não são mais os mesmos, inseridos em redes empresariais e de comercialização, pelas vias primárias ou secundárias, formais e informais.

\section{A produção de software. Desterritorializada?}

O setor de tecnologia de informação, com processo de produção caracterizado pela utilização de conhecimento intensivo e forte imaterialidade, é representativo da compressão espaço-tempo propiciado pelas novas tecnologias. Essa compressão é representada pela revolução informacional que permite comunicações instantâneas globalmente o que, na produção e comercialização, significa controle, eliminando proximidades físicas e permitindo o deslocamento para novos territórios. É a sociedade em rede discutida por Castells (2003), representada pelas redes empresariais de terceirização móveis em busca de menores custos de produção e mão de obra barata. 
A característica flexível própria das tecnologias informacionais é, juntamente com a flexibilidade da utilização da força de trabalho, resultante da organização do trabalho toyotista. Reformulado em sua utilização global, o toyotismo separa cada vez mais o desenvolvimento de tecnologias da produção dos dispositivos de uso dessas tecnologias, assim como generaliza a terceirização globalmente, aprofundando a divisão entre produção do conhecimento e execução.

O desenvolvimento de softwares é um setor que se expande a partir da liberação do marco civil da internet e do aprimoramento de microcomputadores. A informatização dá continuidade ao processo de racionalização do uso de informação nas sociedades capitalistas e vai ficar conhecida como digitalização de objetos e processos (Will-Zocholl, 2016). É jovem em seu tempo de expansão e veio junto com uma ideologia de compartilhamento democrático que, embora na prática tenha sido capturado pela monopolização do setor por grandes empresas globais, mantém um discurso revolucionário em termos de alternativa para um mundo melhor (Sadin, 2016).

Sua flexibilidade está em seu funcionamento por projetos e utilização do trabalho também por projetos, o que torna a força de trabalho móvel e flexível, exigindo atualização permanente e, em tese, autônoma, o que leva, por exemplo, os teóricos do capitalismo cognitivo a prever um caráter potencialmente emancipatório do trabalho (Negri \& Vercellone, 2008; Moulie-Boutang, 2011). É a imaterialidade da produção e dos serviços entranhada cada vez mais em todas as atividades econômicas e não econômicas, impactando todas as relações sociais.

As pessoas trabalham de forma compartilhada em espaços de informação (Boes \& Kampf apud Will-Zocholl, 2016), que integram diferentes lugares, empresas, regiões e países através de terceirizações em ambientes variados globalmente. Embora a virtualização da produção se dê "na nuvem", para que exista exige processos materiais (infraestrutura, equipamentos, processos de trabalho) que viabilizem a rede globalmente.

Na contramão da produção mundial de software, o Brasil se caracteriza majoritariamente pela utilização de trabalho formalizado e menos, como o esperado, pelos contratos por projetos que o tornam flexível desde a origem do setor (MayerAhujaa \& Wolf, 2007; Lima \& Oliveira, 2017). O setor é altamente concentrado mundialmente, dominado por grandes empresas que controlam as linguagens dos algoritmos; no Brasil, a maioria da produção é customizada para clientes, o que possibilita a existência de numerosas micro, pequenas e médias empresas, embora $50 \%$ de toda a produção esteja nas mãos de 3\% das empresas de grande porte, 
multinacionais ou estatais. Os outros $97 \%$ se distribuem por empresas menores distribuídas por todo o país, sendo que $60 \%$ está instalada na Região Sudeste.

A flexibilidade da produção vincula-se à tecnologia informacional, igualmente flexível, e o caráter "imaterial" de sua produção, o que permite caracterizá-la, num primeiro momento, como "sem lugar" (placelessness) (Flecker \& Schönauer, 2016). Em outros termos, é uma produção, ou serviço, que pode ser localizado em qualquer parte do globo, desde que haja uma infraestrutura de internet. Essa infraestrutura possibilita seu funcionamento e depende de grandes investimentos públicos e privados. Não é à toa que no Brasil está concentrada no Sudeste, dado o desenvolvimento econômico da região, da infraestrutura existente, do mercado consumidor e da força de trabalho qualificada. Isso faz com que o lugar em que a empresa se instala defina o alcance, em certa medida, de sua atuação.

Mesmo assim, existe uma distribuição de empresas por todo o território nacional trabalhando para pequenos, médios e grandes clientes nacionais e internacionais. Os processos de modularização da produção e de divisão do trabalho estão mais presentes nas grandes empresas que terceirizam sua produção para outras regiões do país, tal como acontece com as empresas multinacionais. No Brasil, temos vários trabalhadores qualificados trabalhando para empresas internacionais sem sair de suas cidades.

Se nos focarmos na distribuição dessas empresas nacionalmente, também veremos que empresas fora da Região Sudeste se beneficiam de custos menores com a força de trabalho. Se não temos ainda um processo de relocalização, isto se dá pelo tamanho do setor, que ainda é pequeno no país, e seu caráter dependente tecnologicamente, vinculado a cadeias globais de valor.

Com uma característica de conhecimento intensivo, o desenvolvimento dessas empresas se beneficiam da proximidade de universidades e de centros de formação, cujos laboratórios terminam incubando empresas de ex-alunos e professores que prestam serviços para empresas na produção de software e sua manutenção.

Os governos estaduais e as prefeituras atuam no sentido da criação de portos digitais ou distritos digitais que visam oferecer incentivos fiscais e infraestrutura para o desenvolvimento de atividades. Em termos da distribuição regional de estabelecimentos de tecnologia da Informação (TI), o Sudeste concentra $56,8 \%$ dos estabelecimentos, seguido pelo Sul, com $21,9 \%$. O Nordeste aparece com $11,2 \%$, sendo que desse percentual a Paraíba detém $7,1 \%$ do total de estabelecimentos da região, e destes 
$82,3 \%$ contavam com até nove empregados. Ao comparar com o total de vínculos de emprego no estado, seu número é baixo, com apenas 0,6\% (Alves \& Lima, 2020).

No caso de João Pessoa, podemos nos referir aos cursos nesse setor da Universidade Federal da Paraíba, bem como de Campina Grande, a 133,3 km da capital, da Universidade Estadual e dos Institutos Federais, além de faculdades particulares que oferecem cursos no ramo de TI. Com isso temos uma relativa oferta de mão de obra especializada a custo baixo.

A atuação do estado teve início com a constituição, ainda na prevalência da reserva de mercado do Parque Tecnológico de Campina Grande(PaqTecPB), no ano de 1984. Com a expansão da internet, o parque perde protagonismo e João Pessoa passou a concentrar as novas empresas de tecnologia digital. No caso de João Pessoa, em 2019 foi criado o Polo Tecnológico Extremo Oriental das Américas (Extremotec), com o objetivo de atrair e incentivar o desenvolvimento de empresas de tecnologia de informação.

A questão territorial, como enfatizamos, importa e muito. No caso dos trabalhadores, a média salarial em João Pessoa representa 70\% da média salarial da Região Sudeste. Conforme a ocupação, esse número cai ainda mais. Em Campina Grande, a participação na média salarial é menor, sendo $40 \%$ da média salarial de João Pessoa e $27 \%$ da média salarial do Sudeste. Isso mesmo considerando que o índice de escolaridade, ou de formação, é similar (70\% com nível superior).

No caso das empresas locais e dos chamados empreendedores digitais, mesmo trabalhando com clientes nacionais e internacionais, eles se ressentem da imagem regional pela qual são avaliados, ou seja, mais por sua localização espacial e menos pela competência técnica. Isso a ponto de algumas empresas manterem CNPJ no estado de São Paulo para participarem em igualdade de condições com as empresas do Sudeste de editais nacionais de prestação de serviços. Em outros termos, os sentidos do lugar se constituem em métricas de avaliação de competência, mesmo numa atividade placelessness que exige um grau de expertise independentemente do local de atividade.

Nesse caso, não temos uma competência anterior instalada ou alguma tradição, como vimos no caso do setor têxtil e de confecções. O setor de Tecnologia de Informações e Comunicações(TIC) se desenvolve a partir da formação oferecida pela universidade que o impulsiona, e dadas as suas características tecnológicas, permite que se instale. O Estado entra em seguida, para apoiar os atores sociais envolvidos, 
acrescentando um novo significado ao lugar, pelo menos potencialmente, enquanto polo de inovação. Esse novo significado, entretanto, se subordina a hierarquias espaciais e políticas constituídas historicamente.

\section{O deslocamento \\ da indústria "fordista periférica"}

O terceiro caso aqui apresentado, o automotivo, é modelar da internacionalização do século XX da produção em série, altamente mecanizada e que representou a sociedade salarial por excelência: grandes unidades produtivas, trabalhadores organizados e altos salários. Trata-se do fordismo característico da sociedade de bem-estar social, na qual à relação salarial somava-se direitos sociais, com um movimento sindical bastante ativo.

A definição de Lipietz (1989) sobre fordismo periférico de acumulação intensiva, com o crescimento dos mercados de bens finais, pode ser ampliada não apenas para o trabalho qualificado que permanece, em grande medida, nos países centrais, mas para a pesquisa tecnológica que não se espraia globalmente, tal como os outros setores analisados. No caso da indústria automotiva, no Brasil, temos um mercado de consumo local voltado às classes médias e ao consumo de bens duráveis pelos trabalhadores que teve um forte crescimento na última década, favorecendo a expansão do setor automobilístico.

6. No Brasil, desde o início do século $\mathrm{XX}$, empresas como Ford (em 1919) e General Motors (em 1925) implantaram montagens de veículos no país importando todas as peças, sendo que a segunda, na década de 1940, montava ônibus com chassis importado e carroceria feita no país. A International Harvest montou caminhões desde a década de 1930 até os anos 1950. A Fábrica Nacional de Motores (em 1942), empresa estatal, também passou a fabricar caminhões em 1949.
Se, por um lado, a produção de confecções e sua distribuição caracterizam uma diversidade de mercados com forte ênfase nos mercados populares, e uma massa de trabalhadores pouco qualificados, ou seja, uma via secundária da globalização, e o setor de tecnologia da informação já nascer dentro de redes globais, embora o local o reconfigure, falar sobre a indústria automobilística e sua relocalização nos remete às vias principais do grande capital financeiro e industrial e suas estratégias de venda e redução de custos. Mantém-se a convivência desigual e combinada de diversos regimes de acumulação.

A história da indústria automotiva no Brasil começa de forma mais efetiva nos anos $1950^{6}$, com a política desenvolvimentista que estabeleceu incentivo às montadoras para fabricarem no país, exigindo determinado grau de nacionalização de seus componentes. Isso resultou na vinda de algumas empresas como a Volkswagen e a Mercedes Benz (ônibus e caminhões) alemãs, a sueca Scania Vabis, a Simca francesa, a americana Willlis Overland, que produziu carros também sob licença da Renault, e a Vemag que produzia veículos da Auto Union alemã. Por fim, a japonesa Toyota, em 1962, fabricando utilitários. 
A vinda dessas empresas tornou a região do $A B C$ paulista a mais industrializada do país, com a criação de um setor nacional de autopeças que se manteve assim até a abertura comercial dos anos 1990. Marcou também o início do rodoviarismo, com a abertura de estradas de rodagem por todo o país e a redução de investimentos em ferrovias, que foram sendo abandonadas e depois privatizadas apenas para o transporte de grandes cargas. Tornou-se também o berço de um novo operariado nacional marcado pelo fordismo presente nas relações de trabalho, que paulatinamente constituiu uma vanguarda operária que marcou os movimentos pela democratização no Brasil contra a ditadura militar no final da década de 1970, constituindo um novo sindicalismo, combativo e desvinculado do Estado, diverso assim de como era até então. Esse sindicalismo está na origem do Partido dos Trabalhadores (PT) e da Central Única dos Trabalhadores (CUT), que, entre 2003 e 2016, governou o país.

Depois da década de 1950, a primeira multinacional automobilística que se instalou no país foi a Fiat, que montou sua fábrica da região metropolitana de Belo Horizonte, em 1976, marcando o início de um processo de descentralização que irá deslanchar efetivamente duas décadas depois. Com salários mais baixos que suas congêneres em São Paulo, grandes incentivos fiscais do governo de Minas Gerais, a Fiat também se caracterizou por uma gestão mais autoritária, ao contrário das empresas instaladas em São Paulo, que cederam às pressões operárias por maior participação salários e condições de trabalho (Le Vem \& Neves, 1985).

Com as mudanças neoliberais dos anos 1990, novas empresas se instalaram no país dentro já do contexto de globalização, com menores índices de nacionalização. Esse momento vai implicar novas fábricas no interior dos estados: em São Paulo, nas cidades de Sumaré e Itirapina (Honda), São Carlos (Volkswagen), Indaiatuba (Toyota), Piracicaba (Hyundai), Iracemápolis (Mercedes Benz) e Jacareí (Caoa Chery); em Goiás, em Catalão (Mitsubishi) e Anápolis (Hyundai); no Rio de Janeiro, Resende e Porto Real (Nissan, Volkswagen, Citröen-Peugeot) e Itatiaia (Land Rover); no Paraná, Curitiba (Renault, Audi, Volkswagen); no Rio Grande do Sul, Gravataí (GM); em Santa Catarina, Araquari (BMW) e Joinville (GM); em Minas Gerais, Juiz de Fora (Mercedes Bens); na Bahia, Camaçari (Ford); em Pernambuco, Goiana (Fiat); no Ceará, em Horizonte (Troller-Ford) (Bicev, 2019).

Enfim um conjunto amplo de fábricas, todas com grandes incentivos dentro de uma guerra fiscal entre estados e municípios, sem os resultados anteriores de impulso à industrialização regional. No geral, nenhuma dessas empresas desenvolve tecnologias no país e suas fábricas também não primam pelas inovações tecnológicas. Aos trabalhadores, entretanto, há a permanência de relações formais, fordistas, impor- 
tantes num país com a desigualdade social brasileira, mas longe das perspectivas de décadas anteriores.

A Fiat Chrysler Automobiles (FCA) instalou-se em Goiana, cidade com 78.618 habitantes (em 2015), que fica a 57 quilômetros de Recife, e hoje integra sua região metropolitana. A fábrica foi inaugurada em 2015, enquanto polo automotivo. Além da fábrica propriamente dita, estão no polo mais 16 empresas produtoras de componentes e serviços que se instalaram conjuntamente. O polo foi construído no meio de um canavial e produz dois utilitários de luxo, tipo SUV, com parte da produção para exportação. A empresa recebeu, além do terreno (uma área de 11 milhões de $\mathrm{m}^{2}$ ) e da infraestrutura de implantação (como acesso à rodovia), numerosos incentivos fiscais e tributários. Segundo informações no site da fábrica, ela produz cerca de 250 mil veículos por ano, com capacidade de dobrar essa quantia e flexibilidade para a produção de outros modelos. Funciona 24 horas em três turnos e é considerada a mais moderna do Grupo FCA. Emprega em torno de 9.050 trabalhadores entre a fábrica, as "sistemistas" (prestadoras de serviço) e os empregos indiretos.

O impacto no emprego foi alto, sendo que, no acordo com o governo federal, a empresa se comprometeu a utilizar a força de trabalho local, o que aconteceu em grande medida, embora os trabalhadores qualificados venham das capitais próximas, como Recife e João Pessoa, de outras regiões do país e mesmo do exterior.

O trabalho é intenso, baseado em modernas teorias organizacionais que privilegiam a polivalência dos trabalhadores. O salário médio é um pouco maior do que o salário-mínimo nacional e bem abaixo da remuneração dos trabalhadores do setor em outras regiões no país. Na fábrica, o salário médio nominal era (em 2019) de R\$ 2.290,86, enquanto em Betim, sede da Fiat no Brasil, era de R\$ 4.577,40 (Ladosky, 2020). Em São Paulo, nesse mesmo período, o salário médio estava em torno de R\$ 8.571,96 e no Brasil, de $\mathbf{R} \$$ 5.615,69 (Bicev, 2019). Fora da montadora, na cidade de Goiana, a média salarial era em trono de 11⁄2 salário-mínimo.

Goiana é que se poderia definir como greenfield, área com baixa tradição industrial ou trabalho organizado. Soma-se a isso a política antissindical da empresa, que se reflete na baixa sindicalização dos trabalhadores locais. Em fevereiro de 2020, eram apenas quatro trabalhadores sindicalizados, e a aproximação com membros do sindicato traz problemas para os trabalhadores (Ladosky, 2020).

De qualquer forma, é um emprego "fordista" num quadro nacional (e internacional) de desregulamentação do trabalho, sendo que o uso do uniforme da empresa 
é uma forma de distinção entre os trabalhadores locais (Ladosky, 2020). Fora do trabalho, no polo resta a informalidade, os canaviais ou a migração para centros urbanos maiores. A fábrica continua em expansão com indicações até de passar a fabricar outros carros da empresa e diminuir a produção no Sudeste, fechando postos de trabalho num lado e abrindo em outro.

Com a instabilidade política e econômica dos últimos três anos, algumas empresas do setor ameaçam, e outras já efetivaram, fechar unidades no país com a queda de seus lucros. Nenhuma especificidade brasileira. Pressionam por abertura maior de mercados para importar seus produtos, o que já acontece a partir de acordos internacionais. Algumas novas unidades recém-instaladas pouco impactam nos municípios caracteristicamente rurais em que se instalam. A contínua redução de contingente de trabalhadores diminuiu a perspectiva dos trabalhadores em relação a empregos de maior qualidade e melhores salários no setor. Progressivamente, enquadram-se dentro das normas do capitalismo flexível, nas quais a carreira, ou qualquer tipo de estabilidade, é cada vez mais ilusória. Embora os empregos sejam formais, a instabilidade é uma constante. Mas ainda permanecem atraentes frente a um cenário pouco propício para o trabalho. Nos novos territórios, nos quais Goiana se destaca, a expectativa é positiva, dado o cenário de precariedade preexistente, e a fábrica se constituiu numa possibilidade de um emprego melhor.

\section{Algumas conclusões}

O conceito de glocalização destaca a heterogeneidade dos espaços e uma recusa a contrapor o local ao global. A globalização pressupõe localidades, assim com a invenção de tradições (Robertson, 2000). Nos casos aqui estudado, o local encontra-se nas justificativas da implantação de facções numa região com "tradição têxtil"; no local caracterizado como potencialmente de conhecimento intensivo para distritos digitais; na conformação de greenfields, novos territórios para a indústria automotiva, como local sem trabalho organizados. O local resulta, dessa forma, de situações extralocais reais ou imaginárias, que incorpora o capital espacial e o modifica.

Num país de dimensões continentais, convivem no mesmo território formas diversas de empregos, formalidades, informalidades e precariedades. Novos territórios vão sendo ocupados ou reconfigurados em função de interesses de atores sociais que, juntamente com o Estado, atribuem novos significados a lugares, antes à margem do chamado desenvolvimento capitalista, inserindo-os de forma periférica.

As relações sociais existentes se modificam com a entrada de novos atores sociais e o Estado, que reterritorializam o lugar, inserindo-os na globalização, embora 
com ritmos distintos dentro de um mesmo espaço regional, aqui circunscrito ao Nordeste.

Nos territórios estudados neste artigo, convivem formas variadas de incorporação do local em setores produtivos diferenciados, nos quais a formalização do trabalho se dá em processos de terceirização financiados pelo Estado, grandes projetos industriais decorrentes de políticas de desenvolvimento e cluster produtivos que se constituem voluntariamente, com o Estado entrando em seguida para aproveitar seu potencial. Longe de reduzir a presença do Estado, a globalização dá continuidade ao seu papel estruturante do processo de acumulação.

O local se insere em cadeias nacionais e globais de produção, na qual o setor de confecções é representativo, mas não o único. Esse local permite a manutenção de uma produção no país que concorre com a produção importada de confecções, embora permeado de globalizações. Na produção do tecido já fica evidente a presença do artigo chinês, o local se restringindo cada vez mais a processos manuais de estamparia, importantes numa produção que muda constantemente e valoriza os detalhes determinados pela variação da moda.

Vimos situações nas quais a formalidade dominante é relativa, principalmente num quadro crescente de flexibilização do trabalho e reformas trabalhistas. São formais, mas não necessariamente estáveis, variando conforme o setor e a dinâmica econômica. Outras formas reproduzem a histórica informalidade, percebida como precária, mas que, aos poucos, se traveste do flexível "empreendedorismo" em clusters voltados a produtos baratos de consumo de uma população de baixa renda. São consideradas de grande potencial de competitividade em função da capacidade empreendedora de seus produtores.

O caso das atividades em tecnologia de informação, por serem mais recentes, passa pela construção do lugar, estabelecendo suas métricas. Em todo o país, multiplicam-se distritos digitais, dado o espraiamento da tecnologia em todos os setores econômicos e o aquecimento do mercado de trabalho que exige mão de obra qualificada. João Pessoa se insere nessa construção, aproveitando a infraestrutura local de formação de força de trabalho qualificada. O setor trabalha para empresas locais, nacionais e internacionais, mas ainda são consideradas empresas regionais. Uma das empresas estudadas trabalha com informatização bancária para um grande grupo financeiro nacional, outra com informatização de segurança empresarial, atendendo a clientes africanos, as demais customizam seus serviços para clientes locais e regionais. 
O deslocamento das empresas automotivas apresenta maior impacto por suas dimensões, ainda mais quando trazem junto o parque industrial de fornecedores. Esses deslocamentos são acompanhados de relações formais e de diretos sociais diferenciados e se conformam ao município em que se instalam. Ainda trazem a esperança de um emprego diferenciado, em termos salariais, e mesmo de direitos. Porém, nem sempre é assim no conjunto do país, e nem sempre atendem às expectativas locais.

As empresas se transferem enquanto duram os incentivos fiscais, o caráter de greenfield que thes garante menos problemas com trabalhadores organizados e, ainda, enquanto a estabilidade econômica garantir suas vendas. A maioria dos carros produzidos no país pouco tem de populares e pouca relação apresenta com os mercados das regiões em que se estabelecem. Nas regiões mais distantes do centro - estado de São Paulo - isto é mais evidente. A Fiat-Chrysler, instalada em Pernambuco, produz automóveis de luxo que pouco têm a ver com uma população local que antes trabalhava no corte de cana ou na coleta de mariscos. Os trabalhadores qualificados vieram de outras cidades ou de outros estados, e o impacto não foi menor porque junto se instalaram também as fornecedoras de insumos como vidros e autopeças. Além disso, a empresa firmou com o Estado o compromisso de utilizar força de trabalho local.

Embora em situações distintas, a comparação entre setores e diferentes cidades da mesma macrorregião, no Nordeste se evidencia a convivência de formas distintas de produção, mercados e consumos, que se vinculam de forma igualmente distintas com o global. Vias principais e secundárias da globalização que se cruzam, se aproximam e se afastam, representadas pela grande indústria, pela pequena produção familiar, pela pequena produção de tecnologia intensiva, por redes de terceirização. Elas atendem mercados hierarquizados do local ao global, desde as classes média e alta, que consomem carros de luxo, a serviços informáticos empresariais e ao consumo popular. Respondem a demandas globais que se manifestam em marcas e produtos.

Trabalhadores qualificados ou não constituem o substrato do baixo custo presente em territórios periféricos de um país periférico em termos de capitalismo global. Várias periferias se sobrepõem, com significados distintos. Pode ser o trabalhador de software que trabalha formalmente numa empresa; trabalhadores fordistas em uma multinacional automobilística; trabalhadores(as) em facções de confecções para redes de lojas que atuam nacionalmente; e a produção de produtos populares por trabalhadores que trabalham informalmente ou possuem pequenas unidades têxteis no sertão nordestino. 
Para todos estes, numa região de poucas oportunidades econômicas, estas situações significam um cenário de emprego satisfatório e desejado conforme o local. Opção de melhoria de vida, de ocupação regular ou de pequeno negócio que garante a sobrevivência. Por mais distantes que se situem das capitais regionais, esses lugares oferecem atrativos para um capitalismo móvel e flexível, e para o qual o Estado garante a infraestrutura necessária para sua atuação em diversos níveis: regional, nacional e global. Glocalizados, estão presentes nos mesmos espaços, onde o moderno e o tradicional, o formal e o informal, e distintos graus de precariedade confluem na configuração territorial do capitalismo em sua versão brasileira.

\section{Referências}

ALVES, Edvaldo Carvalho; LIMA, Jacob Carlos. A dimensão espacial do trabalho digital: a produção de software na Paraíba. In: LIMA, Jacob Carlos (Org.). O trabalho em territórios periféricos: estudos em três setores produtivos. São Paulo: Annablume, 2020, no prelo.

ARAÚJO, Iara Maria; OLIVEIRA, Daniela. A cidade dos teares: informalidade e subcontratação no Seridó potiguar. In: LIMA, Jacob Carlos (Org.). O trabalho em territórios periféricos: estudos em três setores produtivos. São Paulo: Annablume, 2020, no prelo.

ARBIX, Glauco. Desenvolvimento regional e guerra fiscal entre estados e municípios no Brasil. In: GUIMARÃES, Nadya A.; MARTIN, Scott. Competitividade e desenvolvimento: atores e instituições locais. São Paulo: Editora SENAC, 2001.

BICEV, Jonas Tomazi. Políticas tripartites e ação syndical: a experiência de negociação do Sindicato dos Metalúrgicos do ABS no setor automotivo (Tese de Doutorado) - Faculdade de Filosofia e Ciências Humanas, Universidade de São Paulo, São Paulo, 2019.

CASTELLS, Manuel. A sociedade em rede. Rio de Janeiro: Paz e Terra, 2003.

FLECKER, Jörg; SCHÖNAUER, Annika. The production of "Placelessness": digital service work in global value chains. In: FLECKER, J. (Ed.). Space, place and global digital work, p. 11-30. London: Palgrave Macmillan, 2016.

FREIRE, Carlos. Terceirizações e trabalho informal: o caso da indústria de confecções. In: DAU, Denise; RODRIGUES, Iram J.; CONCEIÇÃO, JEFFERSON, José J. (Orgs.). Terceirização no Brasil: do discurso da inovação à precarização do trabalho. São Paulo: Annablume, 2009.

GIDDENS, Anthony. As consequências da modernidade. São Paulo: Editora Unesp, 1991. 
HARVEY, David. Condição pós-moderna. São Paulo: Loyola, 1993.

KNOWLES, Caroline. Flip-Flop. A journey through globalization's backroads. London: Pluto Press, 2014.

KONTIC, Branislav. Inovação e redes sociais: A indústria da moda em São Paulo. Tese (Doutorado em Sociologia) - Departamento de Sociologia, Faculdade de Filosofia e Ciências Humanas, Universidade de São Paulo, São Paulo, 2007.

LADOSKY, Mario H. A reespacialização da indústria automotiva: o caso da FCA em Goiana (PE). LIMA, Jacob Carlos (Org.). O trabalho em territórios periféricos: estudos em três setores produtivos. São Paulo: Annablume, 2020, no prelo.

LE VEN, Michel; NEVES, Magda de Almeida. A crise na indústria automobilística: automação e classe trabalhadora na Fiat. Ciências Sociais Hoje, p. 113-154, São Paulo: Anpocs-Cortez Editora, 1985.

LIMA, Jacob Carlos. Mobilidade do capital e do trabalho: redes, espacialidades e precariedades na indústria do vestuário. In: PERALVA, Angelina; TELLES, Vera da Silva (Orgs.). Ilegalismos na globalização: migrações, trabalho, mercados, p. 156-170. Rio de Janeiro: Editora UFRJ, 2015.

. As artimanhas da flexibilização: o trabalho terceirizado em cooperativas de produção. São Paulo: Terceira Margem, 2002.

. Novas formas, velhos conteúdos: diversidade produtiva e emprego precário na indústria do vestuário. Revista de Ciências Sociais - Política \& Trabalho, v. 15, p. 121-139, 1999.

LIMA, Jacob Carlos; CORTELETTI, Roseli de Fátima; ARAÚJO, Iara Maria. Empreendedorismo, informalidade e terceirização na produção de confecções: experiências no Nordeste brasileiro. In: LIMA, Jacob Carlos (Org.) O trabalho em territórios periféricos: estudos em três setores produtivos. São Paulo: Annablume, 2020, no prelo.

LIMA, Jacob Carlos; OLIVEIRA, Daniela. Trabalhadores digitais: as novas ocupações no trabalho informacional. Sociedade e Estado, v. 32, n. 1, p. 115-143, 2017.

LIPIETZ, Alain. Fordismo, fordismo periférico e metropolização. Ensaios FEE, v. 10, n. 2, p. 302-335, Porto Alegre, 1989.

MAYER-AHUJAA, Nicole; WOLF, Harald. Working in the german internet industry. Critical Sociology, v. 33, p. 73-99, 2007.

MOULIER-BOUTANG, Yann. Cognitive capitalism. Cambridge (UK): Polity Press, 2011. 
NEGRI, Antonio; VERCELLONE, Carlo. Le rapport capital / travail dans le capitalisme cognitif. Multitudes, n. 32, n. 1, p. 39-50, 2008.

PORTES, Alejandro. Globalization from below: the rise of transnational communities. WPTC-98-01, Princeton University, Sept. 1997.

RIBEIRO, Gustavo Lins. A globalização popular e o sistema mundial não hegemônico. RBCS, v. 25 n. 74, p. 21-38, Out. 2010.

ROBERTSON, Roland. Glocalización: tiempo-espacio y homogeneidade heterogeneidad. Zona Abierta, n. 92-93, p. 213-242, Madrid, 2000.

. Globalização: teoria social e cultura global. Petropolis (RJ): Vozes, 1999.

ROUDOMETOF, Victor. Recovering the local: from glocalization to localization. Current Sociology Review, v. 67, n.6, p. 801-817, Oct. 2019.

. Glocalization: a critical introduction. New York: Routledge, 2016.

SADIN, Éric. La silicolonisation du monde. L'irresistible expansion du libéralisme numérique. Paris: Éditions L'Échappée, 2016.

SANTOS, Milton. Guerra dos lugares. Folha de São Paulo, "Caderno Mais", 8 Ago. 1999.

SAQUET, Marcos Aurélio. Abordagens e concepções de território. São Paulo: Editora Expressão Popular, 2010.

SASSEN, Saskia. Ciudades globales: la recuperación del lugar y las practicas sociales. In una sociología de la globalización, p. 125-164. Buenos Aires: Katz, 2007.

TARRIUS, Alain. La mondialization par le bas. Les nouveaux nômades de l'économie souterraine. Paris : Balland, 2002.

URRY, John. Mobile sociology. British Journal do Sociology, v. 51, n. 51, issue n. 1, p. 185-203, Jan./Mar. 2000.

VÉRAS DE OLIVEIRA, Roberto. O Polo de Confecções de Santa Cruz do Capibaribe. In: VÉRAS DE OLIVEIRA, Roberto; SANTANA, Marco Aurélio (Orgs.). Trabalho em territórios produtivos reconfigurados no Brasil, p. 233-278. João Pessoa: Editora Universitária, 2013.

WILL-ZOCHOLL, Mascha. New topologies of work: informatisation, virtualisation and globalisation in automotive engineering. In: FLECKER, Jörg (Ed.). Space, place and global digital work, p.31-52. London: Palgrave Macmillan, 2016. 